\title{
Reciprocating friction and wear behavior of WC-Co based cemented carbides manufactured by electro-discharge machining
}

\author{
K. Bonny ${ }^{1, a}$, P. De Baets ${ }^{1, b}$, O. Van der Biest ${ }^{2, c}$, J. Vleugels ${ }^{2, d}$, B. Lauwers ${ }^{3, e}$ \\ ${ }^{1}$ Ghent University (UGent), Dep. Mechanical Construction \& Production, IR04, Belgium \\ ${ }^{2}$ Catholic University Leuven (K.U.Leuven), Dep. Metallurgy \& Materials Engineering, MTM, Belgium \\ ${ }^{3}$ Catholic University Leuven (K.U.Leuven), Dep. Mechanical Engineering, PMA, Belgium \\ akoenraad.bonny@ugent.be, ${ }^{b}$ patrick.debaets@ugent.be, comer.vanderbiest@mtm.kuleuven.be, \\ dozef.vleugels@mtm.kuleuven.be, ebert.lauwers@mech.kuleuven.be
}

Keywords: cemented carbide, wire EDM, dry friction, reciprocating sliding wear, pin on plate.

\begin{abstract}
Tungsten carbide based hardmetals with cobalt binder phase are widely used in engineering industries for their excellent mechanical properties and outstanding wear performance. Reciprocative sliding wear behaviour of a number of WC-Co based hardmetal grades was investigated using a small-scale pin-on-plate tribometer. Test samples were manufactured by electro-discharge machining (EDM) with various surface finishing regimes. SEM topographies and cross-section views of the cemented carbides were obtained both before and after dry friction tests, revealing distinctive wear mechanisms. The generated wear loss was quantified topographically using surface scanning equipment. Wear debris particles were collected and examined by EDX and TEM analysis. Based on experimental results, the execution of consecutive gradually finer EDM cutting steps was found to considerably enhance wear performance. Furthermore, a significant influence of contact load, sliding movement duration, application of lubricant and wear debris formation on wear rate and friction was established.
\end{abstract}

\section{Introduction}

Electro-discharge machining (EDM) is one of the non-conventional manufacturing processes that allow to produce complicated shapes in electrically conductive materials irrespective of their strength or hardness: i.e. the strength and hardness is no limitation to the machinability, provided the material is electrically conductive, which is not the case generally for wear resistant ceramics. Today electro-erosion is widely used to machine hardmetals and cermets [1]. More specifically, EDM has successfully proven to be feasible for manufacturing WC-Co cemented carbides. However, difficulties also arise with respect to the control of surface finish, the corrosion of these materials during machining, and the influence the machining parameters may have on final properties such as strength and wear resistance [2-4].

In this paper, several WC-based hardmetal grades with Co-contents ranging from 6 to $12 \mathrm{wt} \%$ were manufactured and surface finished by wire-EDM. The tribological behavior of these WC-Co alloys was compared by performing systematic pin on plate wear tests against WC-Co pins under unlubricated conditions. Scanning electron micrographs of the wear tracks allowed to identify the wear mechanisms. Correlations between wear volume, wear rate and coefficient of friction on the one hand, and material properties and testing conditions on the other hand were elucidated.

\section{Experimental}

WC-Co based cemented carbides. The chemical, physical, mechanical and microstructural properties of the distinctive cemented carbide grades, together with their WC grain size distribution, are compared in Table 1. The cemented carbides cover a wide range of material properties, combining high toughness with high hardness. The $\mathrm{WC} 6 \mathrm{Co}(\mathrm{Cr} / \mathrm{V})$ grade exhibits the highest hardness and stiffness, whereas the highest fracture toughness is encountered with the WC10Co 
grade. The $\mathrm{WC} 10 \mathrm{Co}(\mathrm{Cr} / \mathrm{V})$ grade displays the finest $\mathrm{WC}$ grain structure, with $50 \%$ of the grains being smaller than $0.3 \mu \mathrm{m}$ and $95 \%$ smaller than $0.7 \mu \mathrm{m}$.

Table 1: Physical and mechanical properties, WC grain size distribution and $R_{a}$ and $R_{t}$ surface roughness of the wire-EDM'ed WC-Co cemented carbides

\begin{tabular}{|c|c|c|c|c|c|}
\hline grade & WC10Co & WC12Co(V) & WC12Co(Cr) & WC10Co(Cr/V) & $\mathrm{WC6Co}(\mathrm{Cr} / \mathrm{V})$ \\
\hline Co binder content $[\mathrm{wt} \%]$ & 10 & 12 & 12 & 10 & 6 \\
\hline WC grain growth inhibitor & none & $\mathrm{VC}$ & $\mathrm{Cr}_{3} \mathrm{C}_{2}$ & $\mathrm{Cr}_{3} \mathrm{C}_{2} / \mathrm{VC}$ & $\mathrm{Cr}_{3} \mathrm{C}_{2} / \mathrm{VC}$ \\
\hline density $\left[\mathrm{g} / \mathrm{cm}^{3}\right]$ & 14.33 & 14.08 & 14.01 & 14.23 & 14.62 \\
\hline thermal conductivity $\left[\mathrm{W} \cdot \mathrm{m}^{-1} \cdot \mathrm{K}^{-1}\right]$ & 105 & 95 & 95 & 85 & 90 \\
\hline Vickers hardness $\mathrm{HV}_{10}\left[\mathrm{~kg} / \mathrm{mm}^{2}\right]$ & $1149 \pm 10$ & $1286 \pm 8$ & $1306 \pm 5$ & $1685 \pm 38$ & $1913 \pm 13$ \\
\hline fracture toughness $\mathrm{K}_{\mathrm{IC}}(30 \mathrm{~kg})\left[\mathrm{MPa} \cdot \mathrm{m}^{1 / 2}\right]$ & $>15.5$ & $15.4 \pm 0.5$ & $15.5 \pm 0.6$ & $9.7 \pm 0.2$ & $8.8 \pm 0.2$ \\
\hline E-modulus $[\mathrm{GPa}]$ & $578 \pm 6$ & $563 \pm 2$ & $546 \pm 2$ & $541 \pm 4$ & $609 \pm 4$ \\
\hline Mean grain size, $\mathrm{d}_{\mathrm{av}}[\mu \mathrm{m}]$ & 2.2 & 0.9 & 0.9 & 0.3 & 0.6 \\
\hline WC grain size, $\mathrm{d}_{50}[\mu \mathrm{m}]$ & 1.8 & 0.7 & 0.8 & 0.3 & 0.5 \\
\hline WC grain size, $\mathrm{d}_{95}[\mu \mathrm{m}]$ & 6.0 & 1.8 & 2.1 & 0.7 & 1.2 \\
\hline $\mathrm{R}_{\mathrm{a}}[\mu \mathrm{m}]$ & 0.15 & 0.18 & 0.16 & 0.17 & 0.24 \\
\hline $\mathrm{R}_{\mathrm{t}}[\mu \mathrm{m}]$ & 1.02 & 1.04 & 1.02 & 1.08 & 1.29 \\
\hline
\end{tabular}

The above mentioned cemented carbides were manufactured and surface finished by executing several consecutive gradually finer cuts on a ROBOFIL 2030 (Charmilles Technologies) in demineralised water (dielectric conductivity $5 \mu \mathrm{S} / \mathrm{cm}$ ), using a brass wire ( $\mathrm{CuZn37}$ ) electrode with a diameter of $0.25 \mathrm{~mm}$ and a tensile strength of $500 \mathrm{MPa}$. The generator settings for a number of EDM regimes is given elsewhere [5]. In this paper, the wear performance of WC-Co cemented carbides with the finest EDM regime is investigated. The corresponding $R_{a}$ and $R_{t}$ roughness values are listed in Table 1.

Wear testing. The sliding wear behavior of wire-EDM'ed WC-Co cemented carbides was evaluated using a high frequency tribometer, in which a $\mathrm{WC} 6 \mathrm{Co}(\mathrm{Cr} / \mathrm{V})$ cemented carbide pin was reciprocally slid against WC-Co cemented carbide counter plates, in an air-conditioned atmosphere of $23{ }^{\circ} \mathrm{C}$ and a relative humidity of $60 \%$, in conformity with ASTM G133. The pin material properties are summarized in Table 1 . The tip of the pins was a hemisphere, with average rounding radius and roughness parameters $R_{a}$ and $R_{t}$ of $4.08 \mathrm{~mm}, 0.35 \mu \mathrm{m}$ and $2.68 \mu \mathrm{m}$ respectively.

Contact loads were varied from $15 \mathrm{~N}$ up to $35 \mathrm{~N}$. The stroke length of the oscillating motion was $15 \mathrm{~mm}$. A sliding velocity of $0.3 \mathrm{~m} / \mathrm{s}$ was applied. The test duration was associated with a sliding distance of $10 \mathrm{~km}$, allowing post-mortem wear volumes to be compared. Before each test, the specimens were cleaned ultrasonically with acetone. After each test, the wear topography was quantified using surface scanning equipment (Somicronic ${ }^{\circledR}$ EMS Surfascan 3D, type SM3, needle type ST305). The wear scars were examined by scanning electron microscopy (SEM, XL-30 FEG, FEI, The Netherlands), equipped with an energy dispersion X-ray spectroscopy system (EDS).

\section{Results and discussion}

Friction and wear. Typical and representative wear data, obtained during real-time monitoring of friction and combined wear depth for finish cut wire-EDM WC-Co flat/ WC-Co pin combinations as function of the sliding distance are shown in Fig. 1. Each curve is an average of at least two wear experiments performed under identical conditions, with a standard deviation of less than 10\% between different samples of the same material. The error bars indicating the extent of the variations are excluded to make the figure better readable.

The static and dynamic component of the friction coefficient are found to vary similarly as function of the sliding distance, however at a different level. In all cases, the coefficient of friction and wear depth are noticed to increase abruptly during the first metres of sliding and then gradually 
ascend further during the growing pin on plate contact surface. After a running-in stage, the variations in the friction force curve become marginal, whereas the wear depth increases at an almost constant rate, corresponding to a steady state regime. The wear rate appears to decrease exponentially as function of sliding wear path. The fluctuations in the friction curves, both in the initial and steady state regime, are due to a continuous breaking and regeneration of micro junctions and indicate a more pronounced adhesion of both contact surfaces. The instabilities in the friction curves during running in wear can be related to the changes in the sliding contact surface and removal of the wire-EDM induced top layer. The differences in friction between the cemented carbides can be explained in terms of tribological compatibility and pin-on-plate adhesion, depending on binder content and grain size distribution [6].

The lowest wear volume loss was recorded for the $\mathrm{WC} 10 \mathrm{Co}(\mathrm{Cr} / \mathrm{V})$ grade, whereas the $\mathrm{WC} 10 \mathrm{Co}$ grade exhibits the highest wear damage. The improving trend in wear resistance can be directly associated with material hardness ranking, i.e., WC grain size and binder content.

(a)

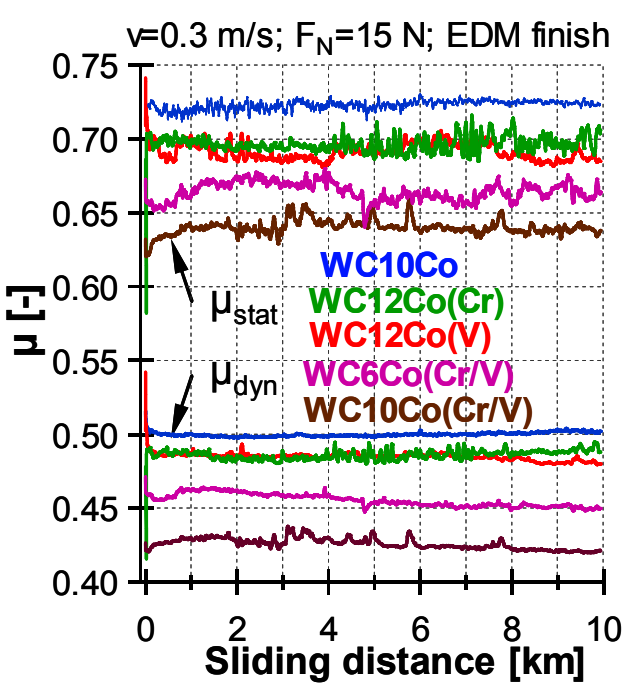

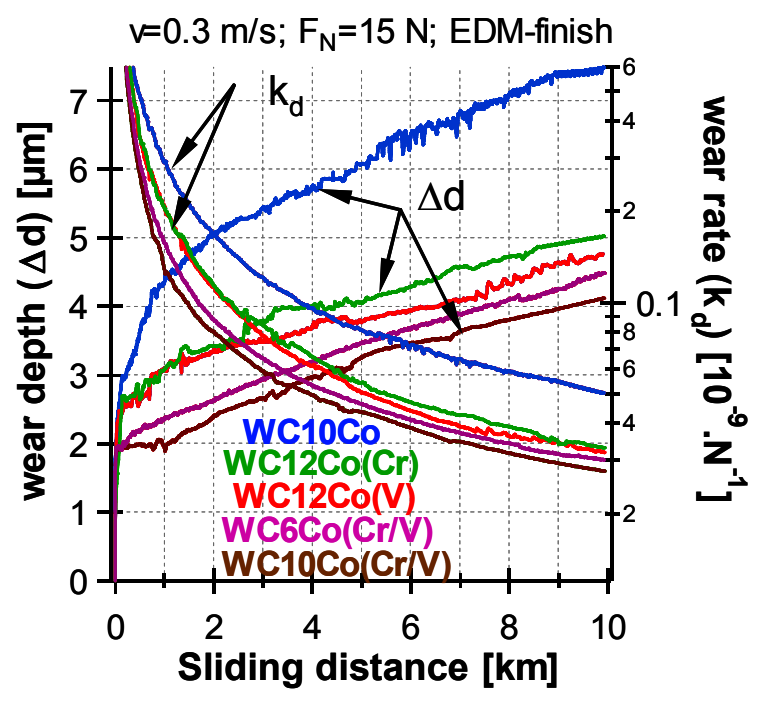

Fig. 1: (a) real-time static and dynamic friction coefficient and (b) wear depth and wear rate for wire-EDM'ed WC-Co flat/ WC-Co pin pairs, sliding at $0.3 \mathrm{~m} / \mathrm{s}$ under a $15 \mathrm{~N}$ contact load

Wear surface analysis. Comparing the tribological response of the distinctive cemented carbides demonstrated that the wear characteristics are affected by the mechanical and microstructural properties and the concomitant wear mechanisms. SEM investigation of the wear scars revealed that wear behavior of the cemented carbides is mainly controlled by abrasion, grain cracking, grain fracture and grain removal, Fig. 2. Within the range of applied surface finishing conditions, the optical appearance of the wear tracks was smooth, indicating that the surface of the composite was polished as a result of the sliding contact with the pin. The normal roughness profile, measured in the wear track of the cemented carbide, yields $\mathrm{R}_{\mathrm{a}}$ - and $\mathrm{R}_{\mathrm{t}}$-values of 0.078 and $1.060 \mu \mathrm{m}$ respectively, which is much lower than the initial values (see Table 1). The microstructure in the wear scar corresponds with the microstructure of the base material, i.e., the grain size of the WC phase is not changed due to the sliding of the pin. However, small amounts of wire-EDM induced recast layer could still be found on the wear (sub)surfaces, Fig. 2.

The softer cobalt binder phase turns out to be removed preferably from the top layer of the WC grains, making them more prone to breaking out from the surface, Fig. 2(b). Based on experimental results, the increasing wear volume with rising contact load can be associated with more pronounced activity of the above mentioned wear mechanisms. Firstly, at higher loads, the adhesive effect of cold welding between pin and plate will increase, which will cause a higher degree of material removal. Secondly, the contact stress increases with the applied load as well, which favors cracking and hence higher levels of plastic deformation and fracture of the cemented carbide. 
(a)

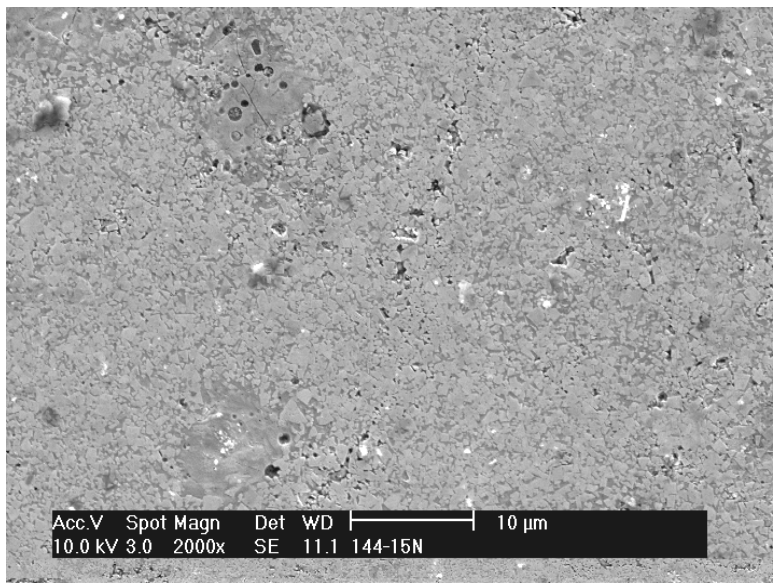

(b)

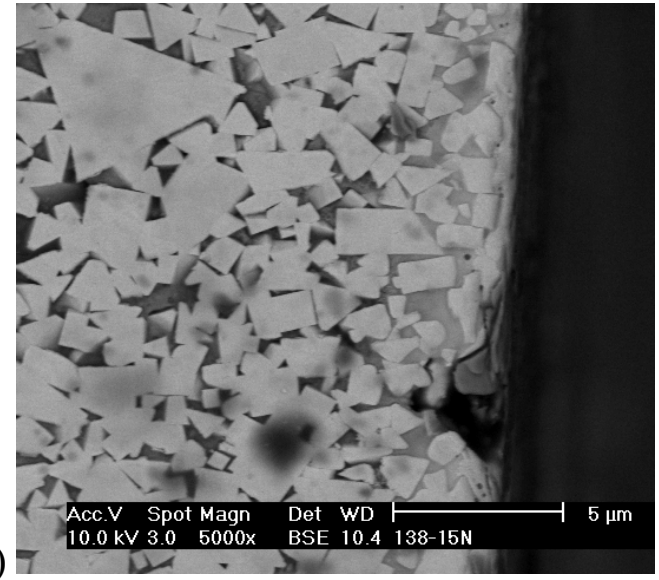

Fig. 2. (a) SE micrograph of wire-EDM'ed $\mathrm{WC10Co}(\mathrm{Cr} / \mathrm{V})$ wear surface and (b) BSE micrograph of wireEDM'ed WC12Co(Cr) wear surface, after sliding $10 \mathrm{~km}$ at $0.3 \mathrm{~m} / \mathrm{s}$ under a $15 \mathrm{~N}$ contact load

\section{Conclusions}

Dry reciprocative sliding experiments on wire-EDM'ed WC-Co based cemented carbides against WC-Co pins revealed several mechanisms involved in their wear process: microcracking, grain pull out, binder removal, grain polishing and abrasion. From wear data, measured during real-time monitoring of the wear depth, it could be inferred that wear rate varies exponentially with the sliding distance. Reducing WC grain size and/or increasing hardness were noticed to considerably enhance the wear resistance. The effect of hardness on wear resistance can be attributed to abrasion as dominating wear mechanism, whereas brittleness is thought to become more important for the wear damage of the highest hardness cemented carbides.

\section{Acknowledgements}

This research was co-financed by the Flemish Institute for the promotion of Innovation by Science and Technology in industry (IWT). The authors gratefully recognize the support and scientific contributions from the Ghent University (UGent) and the Catholic Leuven University (K.U.Leuven). Special appreciation goes to CERATIZIT for supplying the cemented carbide grades.

\section{References}

[1] Kozak, J. Rajurkar, K.P. Chandarana, N. (2004) Machining of low electrical conductive materials by wire electrical discharge machining (WEDM). Journal of materials processing technology, Vol. 146/1-3, 266-271

[2] Jiang, D., Anné, G., Vleugels, J., Vanmeensel, K., Eeraerts, W., Liu, W., Lauwers, B., Van der Biest, O., Residual stress in hardmetals caused by grinding and EDM machining and its influence on flexural strength, Proc. 16th Int. Plansee Seminar, Powder Metallurgical High Performance Materials, Vol. 2 (2005), 1075-1085

[3] B. Lauwers, J. P. Kruth, W. Liu, W. Eeraerts, B. Schacht and P. Bleys, Investigation of material removal mechanisms in EDM of composite ceramic materials, Journal of Materials Processing Technology, Volume 149, Issues 1-3 (2004), 347-352

[4] B. Lauwers, W. Liu, W. Eeraerts, Influence of the composition of WC-based cermets on the manufacturability by Wire-EDM, Transactions of the NAMRI/SME, Vol. 32 (2004), 407-414

[5] K. Bonny, P. De Baets, B. Lauwers, W. Liu, J. Vleugels, S. Salehi, Electrical discharge machinability of WC-Co based cemented carbides and effects on reciprocating sliding friction behavior, submitted to Wear

[6] K. Bonny, P. De Baets, B. Lauwers, W. Liu, J. Vleugels, S. Salehi, O. Van Der Biest, Reciprocative sliding wear behavior of WC-Co Cemented Carbides, submitted to Int. J. Refr. Met. \& Hard Mater. 